\title{
Segurança Alimentar e Nutricional e qualidade de vida em assentamentos rurais
}

\author{
Vanilde Ferreira de Souza-Esquerdo ${ }^{1}$, Sonia Maria Pessoa Pereira Bergamasco ${ }^{2}$, \\ Julieta Teresa Aier de Oliveira ${ }^{3}$, Érika de Souza Oliveira ${ }^{4}$
}

Os assentamentos rurais referem-se a um novo espaço em formação, onde muitos assentados optam inicialmente pelo plantio de gêneros alimentícios para a sua subsistência e depois para o mercado. Assim, a conquista da terra possui significados que vão desde o resgate à cidadania até a melhoria da condição de vida pela aquisição de bens, produtos e serviços. Nesse sentido, este trabalho objetivou analisar a reforma agrária enquanto uma política capaz de contribuir para a melhoria da qualidade de vida e promoção da Segurança Alimentar e Nutricional das famílias assentadas. Para tanto, foi realizada uma revisão bibliográfica sobre o tema. São apresentados também os resultados preliminares da pesquisa em andamento "Segurança Alimentar no Campo". Percebeu-se que a pobreza no meio rural tem uma ligação direta com a concentração fundiária. Apesar da precariedade dos assentamentos rurais, a vida dos assentados, quando comparada a de seus pais, está melhor. Além disso, a vida no assentamento possibilita condições de produção para o sustento da família, podendo assim garantir sua Segurança Alimentar e Nutricional.

Palavras-chave: assentamento rural, pobreza rural, Segurança Alimentar e Nutricional.

\section{Food and Nutritional Security and life quality in rural settlements}

The rural settlements refers to a new space, many settlers have initially chosen the foodstuff plantation for their livelihood and, later, for trading. Thus, the conquest of land has meanings ranging from the rescue of citizenship to the improvement of living conditions through the acquisition of goods, products and services. Thus, this study aimed to analyze the agrarian reform as a policy of life quality improvement and promotion of Food and Nutritional Security of settled families. A bibliographical review was carried out and some preliminary results of the ongoing research "Food Security in Field" are presented. It was found that poverty in rural areas has a relationship with land concentration. Despite the precariousness of rural settlements, the settlers' quality of life has been better than their parents' quality of life. Moreover, living in the settlements enables production conditions to support the family, allowing the farmers to ensure their food security and nutrition.

Key-words: rural settlement, rural poverty, Food and Nutritional Security.

\footnotetext{
1 Pós-doutoranda (Bolsista FAPESP) na Faculdade de Engenharia Agrícola (FEAGRI). Universidade Estadual de Campinas (UNICAMP). Correspondência: Rua Adolfo Maraccini, 139 - Campinas, SP. CEP 13086-010. Tel./Fax 3521-1066. E-mail: vanilde@yahoo.com.

2 Professora Titular na FEAGRI, UNICAMP, Campinas, SP.

${ }^{3}$ Profissional de Pesquisa na FEAGRI, UNICAMP, Campinas, SP.

${ }^{4}$ Mestranda na FEAGRI, UNICAMP, Campinas, SP.
} 


\section{INTRODUÇÃO}

Apresentamos nesse texto uma revisão bibliográfica e dados de pesquisa sobre a importância da reforma agrária enquanto política capaz de promover a melhoria na qualidade de vida das famílias assentadas e, sobretudo, a Segurança Alimentar e Nutricional das mesmas. O motivo da escolha desse tema se deve por sua atualidade e importância.

Os assentamentos rurais fazem parte de uma forma de integração da população rural, num contexto de redistribuição da propriedade fundiária partindo da transferência da população beneficiária e, consequentemente, sua readaptação num novo espaço de vida e de trabalho ${ }^{[1]}$.

Dessa forma, os assentamentos desempenham um importante papel no espaço rural brasileiro devido à contribuição social e econômica que podem gerar com a produção de emprego, a diminuição do êxodo rural, o aumento na oferta de alimentos, os incrementos na produção agropecuária e a elevação do nível de renda, com consequente melhoria na qualidade de vida dos trabalhadores rurais.

Os assentamentos rurais vêm sendo apontados como uma forma eficaz de retorno às atividades rurais das pessoas que migraram para as cidades devido ao processo da modernização da agricultura brasileira. Estudos sobre essa temática comprovam a viabilidade dos assentamentos rurais, no sentido da geração de empregos diretos e indiretos e do estabelecimento de um modelo de desenvolvimento agrícola em bases sociais mais equitativas, mostrando a melhoria de vida das famílias assentadas e o aumento de renda familiar [2].

Em muitos lugares os assentados (e os assentamentos) conseguiram reconhecimento social e político pelos demais setores sociais, superando uma tensão inicial, muitas vezes marcada por uma visão de que os assentados eram "forasteiros" ou "arruaceiros", em especial nas áreas onde os assentamentos foram resultado de ocupações de terra. Em alguns casos os assentamentos chegam a ser vislumbrados como uma saída para a "crise" da agricultura local. Para além das questões econômicas, criam-se novos atores sociais e resgata-se a dignidade de uma população historicamente excluída ${ }^{[3]}$.
Quando se analisa a temática da Segurança Alimentar e Nutricional nos assentamentos percebe-se que a oportunidade de terem uma área para o plantio é condição favorável para a garantia de alimentos à familia seja pela produção de autoconsumo seja pelo aumento de renda.

Nesse sentido, esse artigo objetivou analisar a reforma agrária enquanto uma política capaz de contribuir não apenas para a desconcentração da estrutura fundiária, mas também para a melhoria da qualidade de vida e promoção da Segurança Alimentar e Nutricional das famílias assentadas. Para tanto, foi realizada revisão bibliográfica sobre o tema e são apresentados dados preliminares da pesquisa: "Segurança Alimentar no Campo: redesenhos agroecológicos da produção em áreas de assentamento e remanescentes de quilombos"5.

\section{ASSENTAMENTOS RURAIS E A MELHORIA DA QUALIDADE DE VIDA DAS FAMÍLIAS}

O assentamento rural é uma das formas objetivas de se fazer uma reforma agrária, pois:

\begin{abstract}
De maneira genérica, os assentamentos rurais podem ser definidos como a criação de novas unidades de produção agrícola, por meio de políticas governamentais visando o reordenamento do uso da terra, em benefício de trabalhadores rurais sem terra ou com pouca terra (BERGAMASCO \& NORDER, 1996, p. 7) [4].
\end{abstract}

No contexto da reforma agrária brasileira, o termo assentamento está relacionado a um espaço preciso em que uma população será instalada. Trata-se, portanto, de uma transformação do espaço físico, cujo objetivo é a sua exploração agrícola [1]. Como o seu significado remete à fixação do trabalhador na agricultura, envolve também a disponibilidade de condições adequadas para o uso da terra, como políticas públicas direcionadas a esse setor, e o incentivo à organização social e à vida comunitária.

Do ponto de vista econômico, o acesso à terra é um instrumento de fortalecimento da agricultura familiar, setor dinâmico que

${ }^{5}$ Pesquisa financiada pelo Conselho Nacional de Desensolvimento Científico e Tecnológico/Ministério de Ciência e Tecnologia (CNPq/MCT), Edital CNPq/MCT 19/2010, sob coordenação da Pesquisadora Dra. Julieta T. A. de Oliveira - FEAGRI/UNICAMP. 
emprega a maior parte da mão de obra no meio rural e produz $70 \%$ da alimentação que o brasileiro consome no seu dia a dia. Do ponto de vista político, é fundamental para a modernização do ordenamento territorial do país e o avanço da regularização fundiária, que garantem soberania nacional e segurança jurídica para a produção. Também porque a reforma agrária ajuda a diminuir a histórica concentração da propriedade da terra que ainda vigora no Brasil. Do ponto de vista social, é uma política de combate à pobreza e de ampliação de direitos, como o acesso à moradia, alimentação, saúde, educação e renda. Finalmente, sob o aspecto ambiental, as políticas de reforma agrária e ordenamento fundiário abrem caminho para uma produção agrícola diversificada, livre de agrotóxicos e capaz de ajudar a preservar as riquezas naturais do país (INSTITUTO NACIONAL DE COLONIZAÇÃO E REFORMA AGRÁRIA, 2010, p. 1) [5].

Uma pesquisa inédita sobre qualidade de vida, produção e renda nos assentamentos foi realizada pelo Instituto de Colonização e Reforma Agrária (INCRA) com a consultoria de pesquisadores das Universidades Federais do Rio Grande do Sul (UFRGS) e de Pelotas (UFPel). O levantamento dos dados foi realizado entre os meses de janeiro e outubro de 2010 abrangendo todas as 804.867 famílias assentadas entre 1985 e 2008 , totalizando 16.153 entrevistas em 1.164 assentamentos em todo o país.

Um dos indicadores da pesquisa refere-se ao acesso das famílias às políticas de educação, sendo verificados dados sobre a escolaridade dos integrantes da familia. Verificou-se que a maior parte das famílias assentadas (42,88\%) estudou até a quarta série e $26,97 \%$ entre a quinta e oitava séries [6]. Constata-se que o reduzido nível de escolaridade da grande maioria das pessoas que se ocupam das atividades agrícolas é, sem dúvida, um enorme obstáculo para a melhoria da qualidade de vida no campo, uma vez que compromete o aumento da produtividade do trabalho, do crescimento dos salários e, consequentemente, da renda no campo, contribuindo para a permanência dos graves problemas da pobreza rural [7].

Quando se pesquisa o tema da educação no meio rural e, sobretudo, nos assentamentos, os estudos mostram a significativa mudança quanto à escolaridade dos jovens, os quais são mais escolarizados do que os adultos, indicando para uma grande transformação educacional intergeracional [8]. Nesse sentido, estudos têm demonstrado que os assentamentos rurais favorecem a escolarização das novas gerações $[3,9,10]$.

Uma pesquisa sobre o nível de escolaridade realizada nos assentamentos do Estado de São Paulo ${ }^{6}$ apontou que o nível de escolaridade dos responsáveis é maior do que a de seus antecedentes. Deve-se reconhecer que a situação educacional nesses novos espaços é melhor que a média da população rural, em que a incidência de analfabetismo é superior e a escolaridade alcançada menor ${ }^{[9,11]}$.

Apesar dos índices não serem ainda satisfatórios ${ }^{7}$, o Estado de São Paulo e a Região Sul do Brasil, ainda são os que apresentam melhores índices de escolaridade no meio rural indicando que os agricultores dessas regiões, comparados com o restante do País, frequentam os bancos escolares por um período maior de tempo. Numa análise temporal podese constatar que a escolaridade dos agricultores assentados vem aumentando ao longo dos anos e o acesso à escolarização dos filhos está entre as primeiras demandas das famílias ao serem assentadas.

A inexistência de escolas e de oferta de ensino nos assentamentos ou no seu entorno levam obrigatoriamente os jovens a se deslocarem para os centros urbanos, percorrendo de 5 a até $15 \mathrm{~km}$ de distância de suas residências. A localização da escola dentro do assentamento é fundamental porque ela é um espaço de socialização das novas gerações e de vivência de relações sociais que promovam um jeito determinado de ser calcado nos valores culturais da comunidade; e também a possibilidade de se viabilizar um projeto educacional que contemple as especificidades dos sujeitos, a peculiaridade do trabalho agrícola e os processos culturais enquanto uma matriz escolar [12].

Para os jovens assentados, o estudo assume o sentido da profissionalização, associando ora à ampliação dos conhecimentos sobre a produção

\footnotetext{
${ }^{6}$ Pesquisa realizada por Bergamasco SMPP, Souza VF, Chaves TAB, 2005.

${ }^{7}$ Em 2004 uma pesquisa realizada pela Fundação Instituto de Pesquisas Econômicas/Universidade de São Paulo (FIPE/USP), Instituto Nacional de Estudos e Pesquisas Educacionais/Ministério da Educação (INEP/MEC) Pesquisa Nacional de Educação na Reforma Agrária (PNERA) e avaliou a situação educacional dos assentados no Brasil e constatou que $90 \%$ dos jovens assentados com 18 anos ou mais estavam fora da escola no Estado de São Paulo. Do contingente de 2.865 jovens assentados que frequentavam a escola, ou seja, 9,1\% do total, apenas $4,9 \%$ estavam no curso correspondente com a idade escolar.
} 
agrícola, possibilitando diretamente uma melhoria no trabalho da família no lote, ora a possibilidade de arrumar trabalho mais fácil na cidade. Essa mesma visão ambígua é encontrada também na visão dos pais que querem a permanência dos filhos na terra, mas também a conquista de um bom emprego fora do assentamento, associando ao estudo à melhoria de vida, conforto, família constituída, felicidade, independente da localidade de moradia. Vê-se atualmente que o estudo não garante o emprego dos jovens urbanos, mas para os jovens no meio rural, o estudo ainda guarda essa importância, mesmo que a sua chance de inserção no mercado de trabalho urbano seja difícil. Entre os jovens há uma noção muito clara do papel que a educação assume no desenvolvimento pessoal e coletivo, assim como para o aumento de oportunidades de realização profissional [12].

Verifica-se, em alguns casos, que a situação dos assentados havia melhorado se comparada à situação de seus pais. Esse fato, se aliado a outros fatores, pode ser mais preciso e indicar o porquê da vida, após a entrada no assentamento, ser melhor do que no tempo dos seus pais.

Um importante indicador que avalia a situação atual dos responsáveis é o acesso a alguns tipos de bens, como os eletrodomésticos e veículos. Um número bastante significativo de assentados possui entre os eletrodomésticos, aparelho de som, televisão colorida, máquina de lavar roupa, videocassete, micro-ondas, entre outros. Entre os eletrodomésticos com maior presença está a geladeira, a televisão colorida, o aparelho de som, a máquina de lavar roupas e o tanquinho para lavar roupas (SOUZA et al., 2007, p. 12-13) [13].

Entre os eletrodomésticos que foram adquiridos após a entrada no assentamento estão, principalmente, a antena parabólica, o telefone celular, a máquina de lavar roupas e o freezer.

Muitos benefícios são observados após o estabelecimento de um assentamento de reforma agrária, tanto para o próprio assentado - melhoria na alimentação, saúde, educação dos filhos, moradia [14], como para a região onde está localizado - revitalização do comércio local, aumento da arrecadação do Imposto sobre Circulação de Mercadorias e Serviços (ICMS) [2].

É marcante a percepção dos assentados sobre as melhorias nas condições de vida após o acesso à terra (Figura). A evolução patrimonial das famílias confirma a percepção generalizada de melhoria na qualidade de vida e o principal meio de produção (terra) é percebido como suficiente para as famílias [6].

Figura. Percepção de melhoria para Muito Melhor ou Melhor na condição de vida após o assentamento (em \%). Brasil, 2010

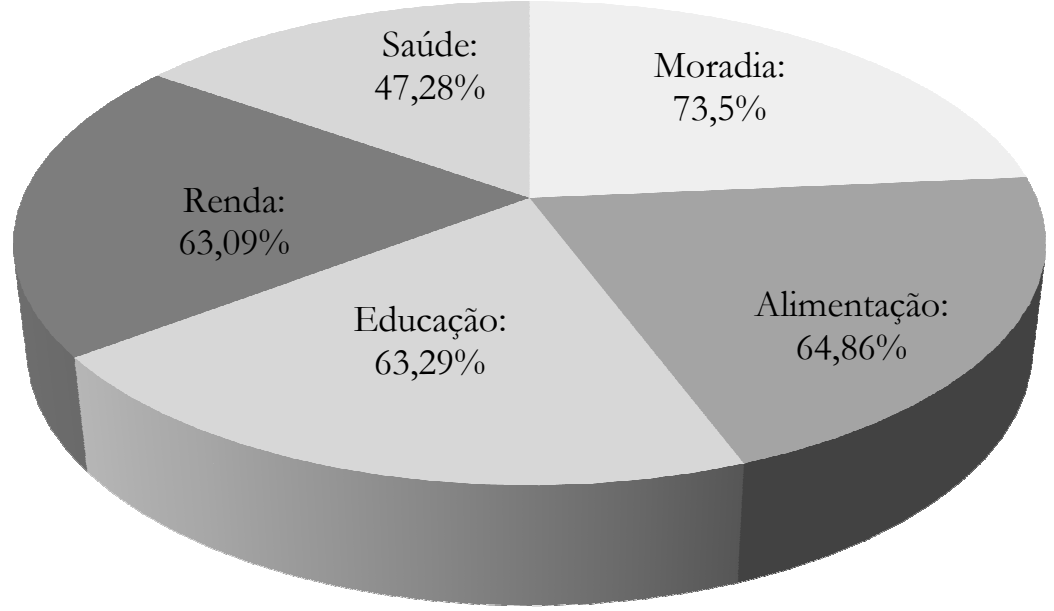

Fonte: Instituto de Colonização e Reforma Agrária (INCRA) [6]. 
Deve-se deixar claro que a melhoria na vida dos assentados é identificada não apenas pelo fato dessas pessoas terem conseguido adquirir determinados bens (eletrodomésticos e automóveis, por exemplo), mas, sobretudo, por questões relacionadas ao sentimento de pertencimento a um sistema produtivo, o qual, em muitos casos, lhes havia sido tirado. Nesse sentido, a melhoria na qualidade de vida dos assentados, significa também o fortalecimento da cidadania dos mesmos [13].

[...] a legitimidade da realização dos programas de reforma agrária associa-se à necessidade de oferecer alternativas aos dramáticos indicadores sociais no campo e na cidade [...]. Nestes aspectos, os assentamentos rurais são avaliados em sua capacidade para aperfeiçoar os padrões de alimentação, educação, habitação, saneamento e emprego de uma significativa parcela da população rural situada entre os piores índices de condição de vida e trabalho no país (NORDER, 1997, p. 59-60) [15]

Políticas que amenizam a fome são importantes, porém quando se fala em erradicá-la ou acabar com a pobreza deve-se apostar numa política estruturante como a reforma agrária, e não apenas políticas compensatórias, pois a reforma agrária transforma o modelo de sociedade, modificando sua realidade, tornando possível aos assentados possuírem o que antes thes era escasso ou lhes faltava.

\section{SEGURANÇA \\ ALIMENTAR (SAN) ASSENTAMENTOS RURAIS} (SAN) como:

Define-se Segurança Alimentar e Nutricional

Realização do direito de todos ao acesso regular e permanente a alimentos de qualidade, em quantidade suficiente, sem comprometer o acesso a outras necessidades essenciais, tendo como base práticas alimentares promotoras de saúde, que respeitem a diversidade cultural e que sejam social, econômica e ambientalmente sustentáveis (CONSELHO NACIONAL DE SEGURANÇA ALIMENTAR E NUTRICIONAL, 2006, p. 4) ${ }^{[16] .}$

Segurança alimentar é, antes de tudo, uma condição para a cidadania, um direito à vida ${ }^{[17,18]}$.
Mas, é somente a partir da década de 1990 que a questão da Segurança Alimentar passa a ser compreendida na complexidade de suas relações com a distribuição da posse da terra no meio rural; com as relações de trabalho no campo; com o que, como e onde produzir; com a distribuição e o acesso aos alimentos produzidos; com a soberania alimentar de nações, povos e comunidades e com as relações internacionais de comércio.

Data desse período pesquisas voltadas para a construção de indicadores diretos para medir a Segurança Alimentar familiar. Dois projetos desenvolvidos nos Estados Unidos deram base para a elaboração de uma escala psicométrica para medir de forma direta a magnitude da Segurança ou Insegurança Alimentar da população. No Brasil essa escala foi adaptada e validada para populações urbanas e rurais por uma equipe liderada pela Universidade Estadual de Campinas (UNICAMP): a Escala Brasileira de Insegurança Alimentar (EBIA) [19].

A EBIA é um indicador eficiente para a identificação e o acompanhamento de grupos populacionais sob risco (nutricional, alimentar, de fome, de Insegurança Alimentar), permitindo classificar/estimar a Insegurança Alimentar nas seguintes categorias [20]:

a) Segurança Alimentar (SA) - quando não há restrição alimentar de qualquer natureza, nem mesmo a preocupação com a falta de alimentos no futuro;

b) Insegurança Alimentar Leve (IAL) situação que não é observada fome entre os membros da família, mas já enfrentando dificuldades no acesso aos alimentos. Identifica a preocupação relativa à possibilidade do alimento vir a faltar, além de problemas com a qualidade da alimentação;

c) Insegurança Alimentar Moderada (IAM) quando os adultos da família passam a sofrer restrições quantitativas na sua dieta;

d) Insegurança Alimentar Grave (IAG) situação na qual a restrição alimentar é de tal ordem que a fome é observada também entre crianças da família.

Utilizando a EBIA, o Instituto Brasileiro de Geografia e Estatística (IBGE), publicou resultados do levantamento suplementar da Pesquisa Nacional por Amostra de Domicilios (PNAD, 2004) sobre 
Segurança Alimentar, realizado em convênio com o Ministério do Desenvolvimento Social e Combate à Fome (MDS). Os dados apresentados sobre Segurança Alimentar refletem as disparidades entre as regiões brasileiras, bem como entre a área urbana e rural.

De acordo com os dados, no Brasil, em 65,2\% dos cerca de 52 milhões de domicílios particulares estimados pela PNAD, residiam pessoas em situação de Segurança Alimentar, porém os dados demonstraram também que em 12,3\% e 6,5\% de domicílios residiam pessoas com Insegurança Alimentar Moderada e Grave, respectivamente. Verificou-se que no meio rural estava a maior prevalência domiciliar de Insegurança Alimentar Moderada ou Grave e, também, a maior proporção de população vivendo nessa condição. Enquanto na área urbana $11,4 \%$ e $6 \%$ dos domicílios estavam em condição de Insegurança Alimentar Moderada e Grave, respectivamente, no meio rural, as prevalências eram $17 \%$ e $9 \%$, respectivamente. Isto significa que cerca de 9,5 milhões de pessoas moradoras em áreas rurais viviam em domicilios com restrição quantitativa de alimentos, ou seja, em Insegurança Alimentar Moderada ou Grave, e 3,4 milhões delas conviveram com a experiência de fome, nos 90 dias prévios à data da entrevista. Esses números em área urbana eram cerca de 30 milhões e 10 milhões, respectivamente [21].

Verificou-se que nas Regiões Norte e Nordeste a Insegurança Alimentar Grave apresentou proporções mais elevadas na área rural $(12,4 \%$ Nordeste e 10,9\% Norte), enquanto no Sul, Sudeste e Centro-Oeste ocorreu o inverso, a Insegurança Alimentar Grave foi detectada em maiores proporções nas áreas urbanas. A proporção da população rural do Nordeste com Insegurança Alimentar Grave era de $17,1 \%$ versus $13,2 \%$ da população urbana, sendo que a Região Norte apresentou a menor diferença entre esses percentuais: $14,4 \%$, na área rural; e $12,7 \%$, na urbana. Nas demais Regiões, onde essa relação se inverte, a proporção de população rural vivendo em domicilios em condição de Insegurança Alimentar Grave foi substancialmente menor, tendo sido a maior, $4,2 \%{ }^{[21]}$.

No Brasil, a existência da pobreza - em muitos casos, da miséria profunda - é resultado do próprio modelo de desenvolvimento implantado, que apoiou: a concentração fundiária que expropria, a tecnologia que desemprega, as relações de trabalho que degradam o trabalhador e a urbanização que esvazia o campo [22].
A conquista da terra pode ser um caminho para reverter a situação de pobreza e, consequentemente, diminuir os índices de Insegurança Alimentar no meio rural brasileiro, pois conquistar a terra significa para muitos assentados o resgate às origens camponesas, sendo tal característica reforçada após essa conquista. Assim, a terra é o fator essencial para a sua reprodução, não possuindo apenas um valor monetário, mas também um valor moral, significando também liberdade em relação a quem os expropriou. A mudança para a terra conquistada significa a possibilidade de iniciar uma nova vida ${ }^{[23]}$.

Nessa nova vida, tendo a própria terra, cujo significado remete ao local de vida e de produção, os assentados podem plantar culturas e criar animais para seu próprio consumo. Nos assentamentos Sumaré I e II, do Estado de São Paulo, os assentados, num primeiro momento, preocuparam-se em produzir, não apenas para o mercado, mas para a própria subsistência, com o cultivo de feijão e a criação de suínos [24].

Nesse sentido, nota-se que a produção para o autoconsumo realizada nos assentamentos contribui para minimizar a situação de Insegurança Alimentar.

A criação de pequenos animais e o cultivo de pomares e hortas caseiras, além da produção de arroz, feijão, milho, mandioca e leite no meio rural, podem contribuir para diminuir ou minimizar a Insegurança Alimentar [...] (DOMBEK, 2006, p. 37) [25].

Se a produção para o autoconsumo for contabilizada e somada à renda dos assentados, pode contribuir para que as famílias mais pobres possam superar tal situação.

Em todo o país muitas famílias assentadas depois de adquirirem a terra conseguiram melhorar sua situação alimentar e nutricional, seja pela produção do autoconsumo, seja pela venda dos produtos oriundos da propriedade.

A utilização da EBIA na pesquisa: "Segurança Alimentar no Campo: Redesenhos agroecológicos da produção em áreas de assentamento e remanescentes de quilombos" [26], realizada em dez assentamentos do Estado de São Paulo ${ }^{8}$, aponta que o nível de Segurança

${ }^{8}$ Assentamentos Araras I, II, III e IV e Ipanema na Região de Campinas; assentamento Tremembé no Vale do Paraiba e Palu, Santo Antonio dos Coqueiros, Rancho Alto e Lagoinha no Pontal do Paranapanema. 
Alimentar e Nutricional para esses assentados melhorou após o acesso à terra. Foram aplicadas questões relacionadas à alimentação dos assentados quando estes ainda eram crianças, ou seja, quando tinham 12 anos de idade (EBIA Pregressa), o que no caso daqueles que não residiam em assentamento nessa idade representa uma proxy de Segurança Alimentar e Nutricional anterior à vida no assentamento. Os dados apontam que um número considerável de assentados aos 12 anos de idade comiam menos do que achavam que deveriam comer, pela falta de dinheiro para comprar comida. Verificou-se essa situação principalmente nos assentamentos Araras I (50\%), Ipanema (44\%), Palu (43\%) e Rancho Alto (43\%) (Tabela 1).

Quando questionados sobre se aos 12 anos de idade acontecia de deixar de fazer alguma refeição porque faltava dinheiro em casa para comprar comida, também houve quantidade considerável de pessoas respondendo positivamente a essa questão. Dentre o universo da pesquisa, esse fato foi mais observado, respectivamente, nos assentamentos Araras IV (39\%), Palu (37\%), Tremembé (33\%) e Rancho Alto (31\%).

Verificou-se também que dentre os dez assentamentos pesquisados no Estado de São Paulo, em nove houve relato de pessoas que na infância ficaram um dia inteiro ou deixaram de realizar alguma refeição pela falta de dinheiro para comprar comida, como pode ser observado na Tabela 1, especialmente no assentamento Palu (34\%).

Muitos assentados projetavam a realização nesse novo espaço de vida e de trabalho o sonho da fartura, que não existia antes do assentamento, chegando a afirmarem que antes de serem assentados e sendo de família pobre, do meio rural, só comeram "mamão até lambuzar" depois que entraram no assentamento, pois com sua terra poderiam plantar uma variedade de frutas que antes não fazia parte de sua alimentação [28].

Os dados preliminares da pesquisa "Segurança Alimentar no Campo: Redesenhos agroecológicos da produção em áreas de assentamento e remanescentes de quilombos" apontam sinais de que a vida antes do assentamento ou no início dele, em termos de Segurança Alimentar, era mais difícil do que nos dias atuais. Ao serem questionados sobre o nível de Segurança Alimentar e Nutricional nos dias atuais através da aplicação da EBIA, registrou-se que a grande maioria dos assentados pesquisados está em Segurança Alimentar, chegando a 100\% no assentamento Araras I, 85\% no assentamento Araras II e no assentamento Santo Antonio dos Coqueiros (Tabela 2).Percebeu-se, ainda, que os dez assentamentos estão em condições de "garantia alimentar", onde são somados os níveis de Segurança Alimentar aos de Insegurança Alimentar Leve, também denominada de "fome psicológica" (possibilidade de vir a faltar alimentos e/ou problemas em sua qualidade).

Há em muitos países uma correlação direta entre acesso à terra e aos alimentos no meio rural. Onde houve um processo de reforma agrária (e certa consolidação do processo) a situação alimentar e nutricional da população encontrou-se adequada, no entanto em locais cuja concentração fundiária é grande torna-se grave a situação de Insegurança Alimentar [29].

Verificou-se, porém, na pesquisa coordenada por Oliveira [26] casos de Insegurança Alimentar Grave, ou seja, quando há situação na qual a restrição alimentar é de tal ordem que a fome é observada também entre crianças da família. Essa situação foi constatada pontualmente em três assentamentos pesquisados. Dois deles localizam-se no Município de Araras, em Araras III onde há uma família nessa situação e no assentamento Araras IV que também conta com uma família. Observou-se também essa situação em um dos assentamentos localizados na Região do Pontal do Paranapanema, no assentamento Lagoinha, onde há uma família nessa situação (Tabela 3).

Cabe destacar a alta porcentagem (correspondente a quatro famílias) com Insegurança Alimentar Moderada e Grave no assentamento Araras IV, tal fato pode ser explicado devido a esse assentamento ser "para rural", caracterizado por lotes pequenos (um hectare) e com características de loteamento urbano, pois localiza-se próximo a um bairro urbano do Município de Araras. Além disso, outro fator agravante refere-se a problemas hídricos na área, dificultando dessa forma a produção agropecuária.

Constatou-se numa pesquisa realizada no assentamento Horto Vergel, localizado em Mogi Mirim (SP), que 70,1\% dos assentados estavam em condições de "garantia alimentar", pois de acordo com a percepção dos assentados, 34,5\% apresentaram Segurança Alimentar e 35,6\% apresentaram Segurança Alimentar Leve (possibilidade de vir 
Tabela 1. Respostas positivas às questões sobre alimentação dos entrevistados adultos aos 12 anos de idade. Assentamentos do Estado de São Paulo, 2011/2012

\begin{tabular}{l|c|c|c}
\hline \multirow{2}{*}{ Assentamento } & \multicolumn{3}{c}{ \% de respostas positivas } \\
\cline { 2 - 4 } & $\begin{array}{c}\text { Comia menos do que } \\
\text { achava que devia }\end{array}$ & $\begin{array}{c}\text { Deixava de fazer } \\
\text { uma refeição }\end{array}$ & $\begin{array}{c}\text { Ficava um dia sem comer ou } \\
\text { fazia apenas 1 refeição }\end{array}$ \\
\hline Ipanema & 44 & 29 & 24 \\
Palu & 43 & 37 & 34 \\
Santo Antônio dos Coqueiros & 28 & 17 & 11 \\
Lagoinha & 36 & 27 & 24 \\
Tremembé & 35 & 33 & 18 \\
Rancho Alto & 43 & 31 & 31 \\
Araras I & 50 & 0 & 0 \\
Araras II & 7 & 7 & 7 \\
Araras III & 31 & 27 & 19 \\
Araras IV & 33 & 39 & 22 \\
\hline
\end{tabular}

Fonte: Segurança Alimentar no Campo: Redesenhos agroecológicos da produção em áreas de assentamento e remanescentes de quilombos (Dados Preliminares) [27].

Tabela 2. Porcentagem de famílias em Segurança Alimentar e Insegurança Alimentar Leve em assentamentos do Estado de São Paulo, 2011/2012

\begin{tabular}{l|c|c|c}
\hline \multirow{2}{*}{ Assentamento } & \multicolumn{3}{c}{ \% de Famílias } \\
\cline { 2 - 4 } & Segurança Alimentar & Insegurança Alimentar Leve & Total \\
\hline Ipanema & 68 & 26 & 94 \\
Palu & 64 & 30 & 94 \\
Santo Antônio dos Coqueiros & 82 & 18 & 100 \\
Lagoinha & 80 & 14 & 94 \\
Tremembé & 65 & 27 & 92 \\
Rancho Alto & 58 & 25 & 83 \\
Araras I & 100 & 0 & 100 \\
Araras II & 85 & 15 & 100 \\
Araras III & 77 & 11 & 88 \\
Araras IV & 39 & 39 & 78 \\
\hline Fony Ses
\end{tabular}

Fonte: Segurança Alimentar no Campo: Redesenhos agroecológicos da produção em áreas de assentamento e remanescentes de quilombos (Dados Preliminares) [27].

a faltar e/ou apresentar problemas na qualidade). Porém havia ainda $19,5 \%$ que apresentaram Insegurança Alimentar Moderada e 10,4\% Insegurança Alimentar Grave [30].

Ao serem assentados, os agricultores se deparam com grandes desafios como o acesso ao crédito para plantio, para moradia, à assistência técnica e extensão rural qualificadas, à garantia de comercialização de seus produtos. Todos esses desafios são condições necessárias para a garantia da Segurança
Alimentar e Nutricional às famílias assentadas. Superálos é realizar uma reforma agrária efetiva e estruturante.

A reforma agrária pode promover impactos favoráveis quanto à Segurança Alimentar, como geração de trabalho e renda, o que contribui para o acesso à alimentação; dá condições para que as famílias assentadas possam produzir seus próprios alimentos e fortalece a "Segurança Alimentar local" uma vez que há produção diversificada de alimentos na região [25]. 
Tabela 3. Porcentagem de famílias em Insegurança Alimentar Moderada e Insegurança Alimentar Grave em assentamentos do Estado de São Paulo, 2011/2012

\begin{tabular}{l|c|c}
\hline \multirow{2}{*}{ Assentamento } & \multicolumn{2}{c}{$\%$ de Famílias } \\
\cline { 2 - 3 } & Insegurança Alimentar Moderada & Insegurança Alimentar Grave \\
\hline Ipanema & 6 & 0 \\
Palu & 6 & 0 \\
Santo Antônio dos Coqueiros & 0 & 0 \\
Lagoinha & 5 & 1 \\
Tremembé & 8 & 0 \\
Rancho Alto & 17 & 0 \\
Araras I & 0 & 0 \\
Araras II & 0 & 0 \\
Araras III & 8 & 4 \\
Araras IV & 11 & 11 \\
\hline
\end{tabular}

Fonte: Segurança Alimentar no Campo: Redesenhos agroecológicos da produção em áreas de assentamento e remanescentes de quilombos (Dados Preliminares) [27].

Numa pesquisa realizada em 2005, coordenada por Segall-Corrêa, cujo objetivo foi verificar a Segurança Alimentar em três assentamentos no Pontal do Paranapanema, constatou-se que:

\begin{abstract}
Os valores encontrados para o Pontal foram: para Segurança Alimentar $(41,1 \%)$ e o de Insegurança Alimentar Leve (40,7\%), ou seja, a "fome psicológica" ou possibilidade de vir a faltar e/ou ter problemas na qualidade, o que nos leva a afirmar que $80,8 \%$ dos assentados estudados estão com condição de "garantia alimentar"; enquanto $14,1 \%$ em situação preocupante (IAM) com restrições alimentares e 4,0\% em situação precária e/ou passando fome (DOMBEK, 2006, p. 64) [25].
\end{abstract}

Para as famílias assentadas pesquisadas cuja renda foi igual ou superior a três salários mínimos mensais não há fome ou restrição alimentar, havendo apenas casos de Insegurança Alimentar Leve (fome psicológica) [25]. A pesquisa "Principais Indicadores Socioeconômicos dos Assentamentos de Reforma Agrária”, realizada entre março e novembro de 1991, demonstrou em $1,1 \%$ do universo de famílias assentadas (828 famílias entre 74.938) que as condições de vida dos assentados seriam, para os mesmos extratos de renda, melhores que outras categorias de trabalhadores rurais, reafirmando a viabilidade dos assentamentos rurais [31].
Os assentamentos rurais contribuem para a diversificação dos produtos agropecuários. Em pesquisa realizada em alguns Municípios no Estado do Rio de Janeiro, verificou-se que os assentamentos significaram uma espécie de reconversão produtiva, com uma reorganização do sistema de uso dos solos, especialmente em regiões antes monocultoras ou de pecuária extensiva [3]. Essa diversidade de produtos possui resultados positivos sobre os próprios assentados, uma vez que a coexistência de produtos destinados à subsistência e de produtos destinados ao mercado, resguarda as famílias de possíveis problemas na comercialização, além de significarem uma melhoria quantitativa e qualitativa da alimentação.

\section{CONCLUSÕES}

A estrutura fundiária brasileira altamente concentrada, com práticas de monoculturas voltadas à exportação, aliado a uma lentidão para a realização da reforma agrária, perpetua a situação da pobreza no meio rural, agravando o quadro de Insegurança Alimentar e Nutricional.

Porém, verifica-se que os assentamentos rurais, apesar dos limites das políticas públicas no meio rural, apontam para a perspectiva do homem do campo ter seu próprio local de moradia, ter seus filhos estudando, trabalhar na sua própria terra, produzindo alimentos e gerando renda para a família. 
Apesar de haver precariedade em muitos assentamentos já instalados como falta de estradas adequadas, de postos de saúde, percebe-se que as familias assentadas acreditam que suas vidas melhoraram depois que entraram nos assentamentos, uma vez que possuem a sua própria moradia, conseguem colocar seus filhos na escola e podem, ao menos, produzir para o seu próprio sustento, garantindo sua Segurança Alimentar e Nutricional. Nesse sentido, a reforma agrária vem reafirmar ser uma política de inclusão social.

\section{REFERÊNCIAS}

[1] Bergamasco SMPP, Blanc-Pamard C, Chonchol M-E. Por um atlas dos assentamentos brasileiros: espaços de pesquisa. Rio de Janeiro: DL/Brasil; 1997.

[2] Bergamasco SMPP, Norder LAC. Os impactos regionais dos assentamentos rurais em São Paulo (1960-1997). In: Medeiros LS de, Leite SP. (Org.). A formação dos assentamentos rurais no Brasil: processos sociais e políticas públicas. Porto Alegre/Rio de Janeiro: UFRGS/CPDA; 1999. p. 75-92.

[3] Leite SP, Heredia B, Medeiros L, Palmeira M, Cintrão R. (Org.). Impactos dos assentamentos: um estudo sobre o meio rural brasileiro. São Paulo: UNESP; 2004.

[4] Bergamasco SMPP, Norder LAC. O que são assentamentos rurais? São Paulo: Brasiliense; 1996.

[5] Instituto Nacional de Colonização e Reforma Agrária. Pesquisa confirma que reforma agrária é um instrumento de combate à pobreza. Publicação Especial do INCRA, ano 1, no 2. Dezembro, 2010. p. 2.

[6] Instituto Nacional de Colonização e Reforma Agrária (INCA). Pesquisa sobre qualidade de vida, produção e renda nos assentamentos de Reforma Agrária do Brasil. MDA/INCRA. Dezembro; 2010.

[7] Hoffmann R, Ney MG. Desigualdade, escolaridade e rendimentos na agricultura, indústria e serviços, de 1992 a 2002. In: XLII CONGRESSO BRASILEIRO DE ECONOMIA E SOCIOLOGIA RURAL, 2004, Cuiabá. Anais... Cuiabá, MT: UFMT, Embrapa Florestas, 2004. p. 1 28.

[8] Molina MC. O Pronera como construção prática e teórica da educação do campo. In: A educação na reforma agrária em perspectiva: uma avaliação do Pronera. In: Andrade MR de O, Di Pierro MC, Molina MC, Jesus SMSA de (Org.). São Paulo: Pronera; 2004. p. 61-88.
[9] Bergamasco SMPP, Souza VF, Chaves TAB. A formação escolar em assentamentos rurais: desafios para as novas gerações. In: Ferrante VLSB, Aly Jr O. (Org.). Assentamentos rurais: impasses e dilemas (uma trajetória de 20 anos). Brasília: INCRA, Araraquara/UNIARA; 2005. p. 389-404.

[10] Castro EG de. A escolarização nos assentamentos rurais: uma caracterização comparada. Est Soc Agric. 1999;12:80103.

[11] Di Pierro MC. Situação educacional dos jovens e adultos assentados no Brasil: uma análise de dados da Pesquisa Nacional de Educação na Reforma Agrária. In: XXIX REUNIÃO ANUAL DA ASSOCIAÇÃO NACIONAL DE PÓS GRADUAÇÃO E PESQUISA EM EDUCAÇÃO, 2006, Caxambu. Anais... Rio de Janeiro: ANPEd, 2006. p. 1-14.

[12] Oliveira JTA, Andrade MR de O. Juventude e projetos de vida: desafios e perspectivas para a agricultura familiar de assentamentos paulistas. In: Bergamasco SMPP, Oliveira JTA, Esquerdo VF de S. Assentamentos rurais no século XXI: temas recorrentes. Campinas, SP: INCRA; 2011. p. 341-64.

[13] Souza VF de, Bergamasco SMPP, CAMBRI, TABC. Trajetórias e redes sociais em assentamentos rurais do Estado de São Paulo: o impacto dos assentamentos na vida dos assentados. In: CONGRESSO BRASILEIRO DE SOCIOLOGIA, 2007, Recife. Anais... Recife: Sociedade Brasileira de Sociologia; 2007. p. 1-17.

[14] Ferrante VLSB, Bergamasco SMPP. Censo de assentamentos rurais do Estado de São Paulo: análise e avaliação dos projetos de reforma agrária e assentamentos do Estado de São Paulo. Araraquara: Multicamp/Unesp; 1995.

[15] Norder LAC. Assentamentos rurais: casa, comida e trabalho [dissertação]. Campinas: Universidade Estadual de Campinas; 1997. 143 p.

[16] Conselho Nacional de Segurança Alimentar e Nutricional (CONSEA). Lei de Segurança Alimentar e Nutricional. Brasília, 2006. [acesso em 13 ago 2012]. Disponível em: https://www.planalto.gov.br/Consea/3Conferencia/St atic/Documentos/Cartilha_CONSEA2007_NOVO.pdf

[17] Maluf RS, Menezes F, Valente FL. Contribuição ao tema da Segurança Alimentar no Brasil. Cadernos de Debate. 1996;6:66-88.

[18] Brasil. Lei no 11.346, de 18 de setembro de 2006. Cria o Sistema Nacional de Segurança Alimentar e Nutricional - 
SISAN com vistas em assegurar o direito humano à alimentação adequada e dá outras providências. Diário Oficial da União, Brasília, 18 set. 2006. Seção 1, p. 1.

[19] Segall-Corrêa AM, Marin-Leon L. A Segurança Alimentar no Brasil: proposição e usos da Escala Brasileira de Medida da Insegurança Alimentar (EBIA) de 2003 a 2009. Seg Alim Nutr. 2009;16(2):1-19.

[20] Segall-Corrêa AM, Escamilla RP, Maranha LK, Sampaio MFA. (In)Segurança alimentar no Brasil: validação de metodologia para acompanhamento e avaliação. Relatório Técnico. 2004 [acesso em 25 out 2010]. Disponível em: http://bvsms.saude.gov.br/bvs/publicacoes/validacao_brasi 11.pdf

[21] Instituto Brasileiro de Geografia e Estatística (IBGE). Pesquisa Nacional por Amostra de Domicílios (PNAD). Segurança Alimentar 2004. Rio de Janeiro: IBGE; 2006.

[22] Wanderley MN. Alcances e limites das políticas de desenvolvimento rural para o combate à pobreza. In: Miranda C, Tiburcio B. (Org.). Pobreza Rural: concepções, determinantes e proposições para a construção de uma agenda de políticas públicas. IICA; 2011. (Série Desenvolvimento Rural Sustentável: Edição Especial). p. 105-107.

[23] Martins VS, Menasche R. Trajetórias do lugar de viver em terras de reforma agrária. Retratos de Assentamentos. 2011;14(1):69-92.

[24] Bergamasco SMPP. Assentamentos Rurais: reorganização do espaço produtivo e processos de socialização. In: Medeiros L, Barbosa MV, Franco MP, Esterci N, Leite SP. (Org.) Assentamentos rurais: uma visão multidisciplinar. São Paulo: EDUNESP; 1994. p. 225-35.

[25] Dombek LA. Autoconsumo e Segurança Alimentar em assentamentos rurais do Pontal do Paranapanema [dissertação]. Campinas: Universidade Estadual de Campinas; 2006. 94 p.

[26] Oliveira JTA. (Coord.). Segurança Alimentar no campo: redesenhos agroecológicos da produção em áreas de assentamentos e remanescentes de quilombos. [Projeto de pesquisa, Edital CNPq/MCT 19/2010, Processo 559493/2010-0] Campinas: Feagri/Unicamp; 2010.

[27] Oliveira JTA. (Coord.). Segurança Alimentar no campo: redesenhos agroecológicos da produção em áreas de assentamentos e remanescentes de quilombos. [Resultados Preliminares] Campinas: Feagri/Unicamp; 2012.
[28] Santos IP, Ferrante LSB. Da terra nua ao prato cheio: produção para o consumo familiar nos assentamentos rurais do Estado de São Paulo. Araraquara: Fundação Itesp/Uniara; 2003. $128 \mathrm{p}$.

[29] Maluf RS, Menezes F, Marques SB. Caderno de Segurança Alimentar [acesso em 15 ago 2012]. Disponível em:

http://ag20.cnptia.embrapa.br/Repositorio/seguranca+alim entar 000gvxlxe0q02wx7ha0g934vgwli72d2.pdf

[30] Guerrero ICO. (In)segurança alimentar no Assentamento Horto Vergel - Mogi Mirim, SP [dissertação]. Campinas: Universidade Estadual de Campinas; 2009. 104 p.

[31] Guanzirolli CH. Principais indicadores socioeconômicos dos assentamentos de reforma agrária. In: Romeiro A, Guanzirolli CH, Palmeira M, Leite SP. (Org.). Reforma agrária: produção, emprego e renda, o relatório da $\mathrm{FAO}$ em debate. Rio de Janeiro: VOZES/IBASE/FAO; 1994. p. 1368. 